\title{
Tame to Torture: Psychosexual Correlations of Sex, Violence and Torture
}

Reynolds $\mathrm{MM}^{*}$

Regis University, United States

\author{
*Corresponding author: Reynolds MM, Regis University, United States
}

Citation: Reynolds MM (2014) Tame to Torture: Psychosexual Correlations of Sex, Violence and Torture. J Forensic Sci Criminol 2(2): 203. doi: 10.15744/2348-9804.1.503

Received Date: January 16, 2014 Accepted Date: April 11, 2014 Published Date: April 14, 2014

\begin{abstract}
This paper discusses the psychosexual correlations and psychological consequences related to torture and behavioral acts that are fundamentally torturous. The influence of participation by learning and the relationship of acts to thought and thought to acts are further discussed to raise awareness to the effects of torture on the torturer. Theories from multiple disciplines are presented in an integrated context to examine the correlation between fundamental psychological principles associated with acts that are torturous in nature and, therefore, innately evil.
\end{abstract}

Keywords: Aggression; Crime; Criminology; Behavioral acts; Human behavior; Psychological effects; Psychology; Psychopathology; Psychosexual; Sex; Sex crimes; Sexuality; Torture; Violence

\section{Introduction}

Torture is contagious. It has a long history. It has been sanctioned by kings and queens, philosophers, poets, judges, saints, popes and the Jesuits [1]. Torture has been used for many purposes. The primary purpose is to elicit information, however, it also been used for other reasons, such as forcing admission of guilt, intimidating political adversaries, and establishing one's power and the superiority of one's group [2].

Establishing "one's power" or control over someone is a recurring theme. Learning by participation is also a major psychological influence. It contributes to the psychological evolution of torturers [2] and can be seen as a major contributor to the addictive quality in the routine performance of many sexually deviant acts as well [3]. The routine performance of torturous acts or behaviors, whether legally sanctioned or not, not only harms the victim physically and/or psychologically, it establishes a foundation of behavior that attempts to disintegrate and consequently annihilate the psychic and moral personality of the victim [1]. The dynamic of torture, or a twist of fate, is that it also annihilates the psychic and moral personality of the perpetrator $[3,1,4]$. Torturous acts are innately evil.

The pursuit of this paper is to present theories from multiple disciplines presented in an integrated context to discuss and describe the correlation between fundamental psychological principles associated with acts that are torturous in nature and, therefore, innately evil. The purpose of this paper is to define and discuss the dynamics of torture and how the act of torture initiates a psychological form of synergism that can compel a relatively tame person into one capable of committing heinous acts of cruelty. The term "torture" is used to describe any act that is "torturous" in nature or product and how these acts progress from tame to torment to torture and "may drift headlong into sadism" [4].

Sex criminality "represents our most disturbing and complex type of criminal behavior" [5]. A high percentage of these sexual killers are sexual sadists who have associated sexuality with violence which usually starts at a young age [5], and progresses in frequency and types of sadistic acts over time [6]. The acts become more violent or bizarre and progress from timid to torturous as they move from the mildest forms of behavioral acts to the most violent behaviors at the farthest end of the spectrum.

\section{Literature Research}

The literature concerning connections between sex and aggression is eclectic and scattered through various disciplines [7]. There has characteristically been little exchange of information between investigators in different disciplines which has resulted in "nonintegrated, esoteric research" [7]. 


\section{Discussion}

Torture is evil. Evil is not a scientific concept with an agreed meaning, but the "idea of evil" is part of a broadly shared human cultural heritage [2]. The "essence of evil is the destruction of human beings" [2]. This includes not only killing, but the "creation of conditions" that materially or psychologically destroys or diminishes people's dignity, happiness, and capacity to fulfill basic material needs [2]. Great evil, explains Staub (1989) "arises out of ordinary psychological processes that evolve, usually with a progressive along the continuum of destruction" [2].

The act of torture morally degrades both its victim and perpetrators [8,1 ]. It "degrades the image of God in the human personhood" of both the victims and torturer [8,1]. The evil of torture, however, is what it does to the torturers [1]. "Torture attacks the human dignity of its direct victims" and "it also victimizes the perpetrators and any society that tolerates its practice" [8]. The torturer also "undergoes a moral violation and the practice of torture strip him of his own God-given nobility" [1]. Thus, "a torturer inflicting torments and suffering on a victim not only defaces another brother or sister, but implicitly attacks the face of God in the other, and destroys human community" [1]. Torture contaminates society [8].

Torture is also personally destructive to the torturers because of the intent to diminish or even destroy the personhood of their victims. It is this "subjective, interpersonally destructive aspect of torture that makes it different and morally worse than many other destructive aspects of war" [1]. It is even worse than suffering or causing death in combat. The act of torture is that it is "utterly incompatible with the dignity of the human person and the practice of torture wounds the victim, the perpetrator and the common good of all" [8].

The methods of torture have changed from the "medieval museum of horrors" to other forms of psychological manipulation which frequently induce feelings of "powerlessness and despair" [4]. The "task of torture" is especially gratifying to those with narcissistic tendencies since there is no activity that "so effectively allows someone to make one's own whims and desires the absolute focus of the victim's attention" [1].

Power and control are the primary motivational factors relating to persons who perform torturous acts or engage in sexually deviant practices [3]. The master-slave relational theory is used to help understand the dynamics of domination and submission; and, how this correlates to the dynamics of torture. Torture is all hierarchy [4]. It is intensified, magnified and brought back to its archetype and most brutal level through the "archaic pairing of master and slave" [4]. Power and control remain at the root of all evil.

Torture is generally considered an evil act since it is the intentional and methodical infliction of great suffering upon another person or group of persons [9]. Torture, according to the Random House Webster's Unabridged Dictionary, Second Edition, refers to the infliction of severe pain, especially as a means of punishment, revenge, coercion or for sheer cruelty causing extreme anguish of body or mind [10]. A straightforward beating, for example, is the most common form of torture [4]. Sexual sadism is considered the most brutal form of torture due to the underlying sexual excitement resulting from the infliction of pain, suffering or humiliation to another person $[6,3,9]$.

Torture is evil at many level and degrees. The term "tame" is used to represent the mildest or lowest form of aggressive behavior. The mild, meek, timid or passive behavioral acts are considered tame due to the docile and subtle level of behavior. Tame, therefore, is the first degree or level of behavior that is non-aggressive or non-threatening in nature or product. It is analogous to the first step of a long ladder with torture representing the final rung.

The term "taunt" represents the next level or degree of aggressive or violent behavior. Taunt is a form of teasing or provocation that is challenging or insulting in manner [10]. This could include something as simple as a verbal threat or an insulting sarcasm. The act of taunting would be considered a moderately aggressive behavior designed to provoke, irritate or annoy the other person.

The term "torment" refers to the act of repeatedly inflicting physical or mental suffering on another person [10]. The repetition of the behavior induces a reinforcing or classical conditioning effect on the participants which is analogous to the master-slave scenario [3]. The act of "torment" is particularly deceiving because it can manifest itself through various overt behaviors, whether innocent or criminal and, through these interactions, create both a systematic and synergist environment causing a psychologically intoxicating effect on the tormenter.

\section{Psychological Consequences of Torturous Behavior}

Servicemen, police officers and other individuals who are predisposed to obedience, either through ideological convictions or training, often find themselves in situations where they are ordered to commit atrocious acts, which increase the possibility that they will become "inflictors of pain" [1].

Schluz (2007) reminds of us Milgram’s (1963) psychological study of obedience to authority, "The Perils of Obedience," which 
demonstrates how ordinary people simply doing their jobs and, without any particular hostility on their part, can become agents in the destructive process of torture [4]. Milgram's study was conducted in the early 1960s. Results showed that 65 percent of the participants would administer high levels of electric shocks to other people when an authority figure told them to do so [11]. This study further showed that people who may be unlikely to be cruel or tortuous in everyday life will inflict pain on others if told to do so by someone in a position of authority [11]. Obedience to persons in positions of power is a strong motivation for people to perform acts they might not otherwise commit.

Gibson and Haritos-Fatouros (1986) reminds us of another psychological study conducted at Stanford University by psychologists Craig Haney, W. Curtis Banks and Philip Zimbardo which demonstrated how quickly and easily university students can be conditioned to perform controlling, abusive and torturous acts on fellow students within a few days simply because a person in a position of authority, in this case the professors, told them to do something. The students were divided into two groups to act as either prison guards or prisoners. Within six days' time, the typical college students changed into controlling, abusive prison guards while those chosen to be mock prisoners became helpless, passive and dependent. The Stanford experiment was abruptly stopped after students started crying, became depressed, and developed psychosomatic illnesses [11].

It could easily be argued that college-aged university students might be more easily influenced by persons in positions of authority than older adults. However, combat soldiers, despite military training designed to desensitize persons to violence and, therefore, reduce the psychological reaction normally created by repulsive acts, have frequently reported their psychological suffering as a result of following orders to kill or torture others [11]. Vietnam veterans, for example, have experienced long-term psychological consequences as a result of committing horrendous acts during war [11,12]. These veterans have described and discussed feelings of anxiety, guilt, depression and an inability to maintain intimate relationships [11]. Post-traumatic Stress Disorder (PTSD) is a common diagnosis for many veterans returning from war [12].

In addition, Schluz (2007) describes how military recruits and police officers may easily develop sociopathic tendencies simply by doing their job [4]. The violent synergism generated through tortuous types of behavioral encounters and exchanges activate a type of psychological power struggle between the conscious and unconscious mind that is analogous to the power struggle between a sociopath and their victim(s). The violent synergism generated is another example of the master-slave scenario with the officer acting the role of master or torturer and, therefore, is subconsciously exposed to the underlying dynamics of torture and the psychosexual connection to arousal.

\section{Contagion of Torture}

Perry (2005) describes "contagion of torture" as a secondary evil of torture which is fundamentally the spread or transmission of diseased thinking or "logic of justification" which, combined with repeated performance, creates a perversion of thought that permeates society both by law and by action [1]. Secondly, the "logic justifying torturing one's fellow human beings in one particular situation can be used to justify torture in other similar situations, and the practice can become widespread and pervasive" [1]. The contagion or transmission of torture occurs through training programs and alterations to arrest procedures [1]. As a result, the police departments become the medium by which a contagious disease is transmitted. This is the contagion problem of torture [1].

The use of less-lethal weapons, such as stun guns, electronic shock devices and other types of less-lethal weapons is one example of the types of routine and repetitive negative and aggressive behaviors that can seduce the police officer into a form of interplay that can be personally deceptive and unintentionally self-destructive. The use of these types of less-lethal weapons, for example, seems to be a reasonable and justifiable alternative to helping police officers apprehend citizens without killing them. The problems occurs, however, when these same devices create an environment in which the police officer performs acts of torment or taunting or other types of torturous behaviors while attempting to subdue or arrest a suspect. The less-lethal weapon prolongs the apprehension of a suspect or the suspension of an illegal activity, while simultaneously creating a torturous environment for both the police officer and the citizen. Without a thorough understanding of the psychological undertow involved with the dynamics of torture or the psychosexual correlations of sex and violence, persons in positions of power or authority become vulnerable to the psychological consequences of tortuous behaviors and, thus, become victim to the laws of nature.

The use of less-lethal weapons also serves as an example of how torturous behaviors can appear reasonable in one situation and, thus, lulls the police officer, policy makers and the voting public into a false sense of justification that permeates society with each brutal action. Less-lethal weapons contribute to the contagion of torture. Depending upon one's perspective, explains Staub (1989) [2], the most kind or brutal actions can appear reasonable and justified to people [2]. The use of less-lethal weapons, for example, appears reasonable and becomes seemingly justifiable when society views it as a less aggressive method of apprehension when, in fact, it creates a more aggressive and torturous environment for both the police officer and the citizen.

Persons in positions of power or authority are equally susceptible to receiving pleasure or positive reinforcement from the same sense of power that entices and intoxicates the sadist. Hazelwood and Michaud (2001) describe how the sadist receives pleasure 
through the domination and submission of another person [3]. Most often the pain is inflicted to subordinates or perceived inferiors. The pleasure for a sadist is his perception of himself to be "a god" and through his victim proves his "godlike omniscience" [3]. Sexual sadists are particularly intoxicated by the gratification received from having or "achieving power or control over someone" [3]. Persons in positions of power or authority are prone to similar psychological reactions due to their repeated performance of dominating acts that are positively reinforced through self-satisfaction, job performance ratings and/or societal expectations; however, these same behavioral acts also produce negative psychological consequences associated with any act that is fundamentally tortuous. Torture is evil at many levels and degrees.

\section{Psychosexual Correlations of Sex, Violence and Torture}

The psychosexual correlations of sex, violence and torture can be further explained using Sigmund Freud's (1856-1939) theories of sexuality. Freud's theories continue to provide the foundation from which others can attempt to understand or discuss human psychology and the underlying motivations behind human behavior. Freudian thinking is still "very much alive in contemporary psychology" [7].

Freud elaborated on these theories throughout his career and they have been "generally accepted not only by psychoanalysts, but by laymen, men of letters, and scholars in a variety of specialized areas of study" [13]. Freud's theories have also been supported by criminologists and researchers who studied serial killers and developed personality characteristics and typologies [5]; most of whom have concluded their research with similar findings regarding the correlations of sex, violence, aggression and torturous acts.

Freud's theory of sexuality regarding the psychosexual nature of human behavior is used to describe and compare associated personality traits and other characteristics developed by criminologists to explain sex crimes, sexual homicides and the sadistic personality. Freud theorized that there is a "repressed or unconscious sexual motivation" behind nonsexual acts [13]. Criminologists have since discovered that some arsonists start fires, an apparent nonsexual act, but that there underlies a sexual motivation for the behavior [3]. Thus, arson is another "non-sexual crime" for which a "perverted libido" is most often cited as cause or explanation [13].

\section{Masturbation}

Masturbation is a form of personal torture. The sin of masturbation is not that it is an act related to sex. The sin is that it is an act of self-abuse. The madness or insanity of masturbation can be understood when compared to the fatal results achieved when compulsive masturbators become practitioners of sexual asphyxiation. Masturbation is a form of autoeroticism which potentially progresses along the continuum of destruction towards accidental death or suicide.

The Catholic Church has always taught that masturbation is intrinsically evil and a seriously disordered act which serves as a serious obstacle to integrating sexuality into the personality and to maintaining psychological health [14]. Freud would agree. Freud's theory regarding the "developmental account of morality" maintains that the process works only by reliance on psychical reactionformations in which "individual aggressiveness is turned back on its possessor in the form of conscience" [15]. This boomerang effect to one's conscience is analogous to the dynamics of torture and its effects on the torturer.

Farraher et al (2013) further explain that the harmfulness of masturbation is that it is a fantasy-driven, self-centered act that damages the ability to develop into a mature person capable of maintaining a healthy personality and foster an emotionally stable relationship with others [14]. It predisposes individuals to overreact in anger, intensifies loneliness and may lead to a sexual addiction [14]. Similar to other types of addiction, the addicts find they need to increase the stimulus to achieve the same effect. Thus, individuals who masturbate create a situation that encourages the habit of masturbation requiring additional stimulus to achieve orgasm. What may begin as a simple act of pleasure develops into a complicated behavior in an effort to achieve a temporary sexual high. Once the habit of masturbation is established, it is difficult to break [14].

\section{Sexual Asphyxiation}

Sexual asphyxiation is an example of personal torture practiced to the extreme. Sexual asphyxiation is considered a form of personal torture due to the dangerous nature of this self-imposed, self-gratifying desire to achieve greater heights of physical and psychological gratification [3]. Practitioners of sexual asphyxiation or autoeroticism may act out fantasies with elements of "torture, abuse, execution, helplessness, and sexual arousal through risk taking" [3]. Being a "thrill seeker is "consistent with being a seeker of autoerotic gratification" [3]. Masochism, fetishism, and sexual bondage are three deviant behaviors commonly associated with practitioners of sexual asphyxiation [3]. The practice of autoeroticism may also be considered a form of narcissism and, therefore, sinful due to the inordinate absorption in oneself. It could also be argued that autoeroticism is as a form of sexual sadism because it is simultaneously violent and sexual.

Those who practice autoeroticism create conditions conducive to suicide or solo death [3]. The risk of death is known; yet the 
individual is psychologically conditioned to and physically aroused by the risk or introduction of violence into a sexual situation. It becomes a form of self-induced intoxication that begins at one end of the violence continuum and progresses beyond boundaries to the furthest extremes of sadism. The level of violence increases as the practitioner becomes desensitized to the violent acts previously performed and, therefore, needs to increase the level or type of violence in order to achieve the level of gratification desired. This produces a need to repeatedly "perform" certain behavioral acts which are again reinforced through physical and psychological satisfaction. The dynamics involved with the practice of sexually deviant acts are similar to the dynamics of torture. It becomes addictive [14,3]. The "answer lies in the practice itself" [3].

\section{Rape}

Next to sexual murder, "forcible rape is considered the most violent type of sex crime [5]. The rapist, for example, uses sex as a tool of aggression. The motivating factor for the rapist is not the enjoyment or satisfaction received from the act of sex but, instead, from the "act of aggression" that produces the intoxicating ingredient they crave [3]. The rapist takes "great pleasure in surveying his victim's torment"[7]. In rape, "aggressive impulses may dominate sexual ones to the point where the sexual activity becomes entirely secondary" [7].

The International Journal of Offender Therapy and Comparative Criminology, reports similar findings with emphasis on the rapist's sadistic behavior which often includes degrading and humiliating the victim [16]. The rapist rarely kills because they want to continue to torture the victim. The pleasure for the rapist is received from witnessing the suffering of the victim which is often required in order to achieve orgasm. Necrophilia, the practice of seeking intercourse with corpses, is another example of a "rape-related form of sexuality" [7]. Additionally, rape is often associated with other forms of violence [5].

\section{Sexual Bondage}

Sexual bondage is another example that involves the psychosexual arousal from the binding and control over another person (sadism) and/or arousal from being bound and controlled by another (masochism) [3]. Some subjects of torture, according to the CIA Manual's section on "Coercive Techniques," were found to exhibit symptoms of masochism and withheld information they might have otherwise divulged in order to be punished [4]. They enjoyed the pain [4].

\section{Sadomasochism}

Zillman (1984) considers sadomasochistic behavior to be the most perplexing and confusing "sex-aggression fusion" where "aggression is placed in the service of euphoria" [7]. The extent of sadomasochism in contemporary Western societies is not accurately known because sadomasochism is usually practiced in secrecy [7]. Data has shown, however, that sadomasochists perceive their sexual preference as deviant and, presumably as a result, hide it from others [7]. Freud considered it "obvious that sadism is nothing more than the occurrence of this trait in exaggerated form" [7]. Freud's reasoning on masochism is less straightforward, but once described it as a "secondary dynamic that results from the inversion of sadism" [7].

The ritualistic performance of certain behaviors contributes to the intoxicating effects of the sense of power. The aggressive behavior becomes the stimulating factor that is sexual in nature because it increases activation of the libido which further intensifies the search for gratification. The progression for the sexual sadist begins with fantasy then graduates to solo sex causing the behavior to intensify in frequency and severity $[6,3,9]$. Many serial killers exhibit characteristics of sexual sadism which often began at a young age and progressed to the commission of multiple murders in efforts to achieve sexual satisfaction [9].

\section{Conclusions}

Studies have shown that learning by participation contributes to the psychological evolution of personal destruction through the performance of acts that are innately torturous in nature, if not by law. Psychosexual correlations to sex, violence and torture were discussed using Freudian theories of sexuality and compared to behavioral characteristics and typologies developed by contemporary criminologists. The act of torture initiates a psychological form of synergism that can compel a relatively tame person into one capable of committing heinous acts of cruelty. These acts progress from tame to torment to torture and may drift "directly into sadism".

The dynamics of torture were shown to be psychologically destructive to both the victim and the torturer. The use of less-lethal weapons by law enforcement was used as an example to demonstrate how violation of this basic principle contaminates the individual serviceman or police officer and contributes to the contagion of torture. Torture is contagious.

The act of torture reinforces the psychological justification for it, yet it remains a moral affront to God, a personal affront to one's dignity whether victim or perpetrator, and an assault on one's conscience by producing psychological consequences which create a vicious cycle that escalates through participation and practice. Hence, the slippery slope. 
Torturous acts, whether performed against oneself as in the performance of masturbation, against another person for purposes of cruelty or sexual arousal, or simply in the line of duty in the performance of one's job, initiates a psychosexual dynamic that once begun may never end. Torture is innately evil.

\section{References}

1. Perry J (2005) Torture: Religious ethics and national security. Orbis Books, New York, United States.

2. Staub E (1989) The roots of evil. Cambridge University Press, Cambridge, England

3. Hazelwood RR, Michaud SG (2003) Dark dreams: Sexual violence, homicide, and the criminal mind. St. Martin's Press, New York, United States.

4. Schluz W (2007) The phenomenon of torture: Readings and commentary. University of Pennsylvania Press, Pennsylvania, United States.

5. Flowers RB (2001) Sex crimes, predators, perpetrators, prostitutes, and victims. Charles C. Thomas Publisher Ltd, Springfield, Illinois, United States.

6. Fahmy A (2012) Sexual sadism. The Gale Encyclopedia of Mental Health 1407-10.

7. Zillmann D (1984) Connections between sex and aggression. Lawrence Erlbaum Associates Publishers, Hillsdale, New Jersey, United States.

8. Colecchi SM (2010) No excuses for torture. America Press Inc, United States.

9. Stone MH (2010) Sexual sadism: a portrait of evil. J Am Acad Psychoanal Dyn Psychiatry 38:133-57.

10. Random House (2001) Random House Webster's unabridged dictionary, 2nd edn. Random House, New York, United States.

11. Gibson JT, Haritos-Fatouros M (2005) The education of a torturer. Psychology Today, Sussex Publishers, New York, United States.

12. Reynolds MM (2006) Hearts without homes: Coping with PTSD. Vietnam magazine, Weider History Group, United States.coping-with-ptsd.

13. MacNamara DE, Sagarin E (1977) Sex, crime and the law. The Free Press, New York, United States.

14. Farraher JJ, Friedrichsen T, Fitzgibbons RP (2013) Masturbation: New Catholic Encyclopedia Supplement 2012-2013. Ethics and Philosophy, Ed. Robert L. Fastiggi 3: 963-966.

15. Crittenden P (1990) Learning to be moral. Humanities Press International Inc, New Jersey, London.

16. Palermo GB (2013) The various faces of sadism. Int J Offender Ther Comp Criminol 57: 399-401.

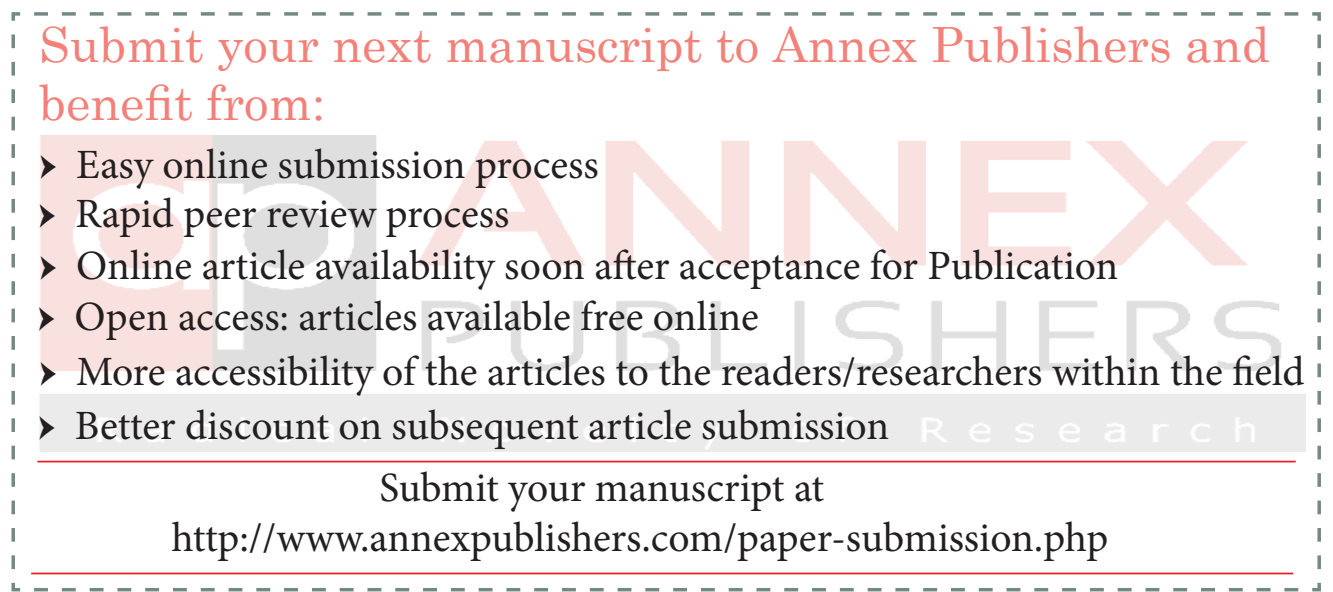

